\title{
Development of New Formulations of Biologics: Expectations, Immunogenicity, and Safety for Subcutaneous Trastuzumab
}

\author{
Franklin Fernandes Pimentel ${ }^{1} \cdot$ Gilberto Morgan $^{2} \cdot$ Daniel Guimarães Tiezzi $^{1} \cdot$ Jurandyr Moreira de Andrade ${ }^{1}$
}

Published online: 24 September 2018

(c) The Author(s) 2018

\begin{abstract}
Subcutaneous (SC) trastuzumab has long been approved as a cancer treatment for early and advanced HER2-positive (HER2+) breast cancer by both the European Medicines Agency (EMA) and Agência Nacional de Vigilância Sanitária (ANVISA), the Brazilian National Health Surveillance Agency. A pivotal non-inferiority phase III trial, which aimed to provide a more convenient and cost-effective treatment in the HER2+ breast cancer neoadjuvant setting, showed that the SC group met prespecified efficacy endpoints and the SC formulation was considered as safe as the intravenous (IV) formulation. Considering the recent approval of several biosimilars, new SC formulations are also an interesting manufacturer strategy as these drugs can obtain patent protection. Despite being considered non-inferior to the IV formulation of trastuzumab, in clinical development, the SC formulation elicited higher immunogenicity, mainly related to overall anti-drug antibodies (ADAs); however, this finding was classified as clinically non-significant. In this article, we explore different aspects of the benefits and risks of the SC trastuzumab formulation according to published data.
\end{abstract}

\section{Key Points}

Formulation of new biologics to be used as subcutaneous (SC) injections is a developmental strategy aimed at improving patient comfort and/or reducing costs.

SC trastuzumab is a therapeutic option approved to treat HER2-positive (HER2+) breast cancer in Brazil and Europe.

To date, there are no safety or efficacy data on SC trastuzumab and intravenous pertuzumab combination therapy.

Franklin Fernandes Pimentel

fpimentel@gmail.com

1 Breast Disease Division, Department of Gynecology and Obstetrics, Ribeirao Preto Medical School, University of Sao Paulo, São Paulo, Brazil

2 Department of Oncology, Skåne University Hospital, Lund, Sweden

\section{Introduction}

Trastuzumab received US Food and Drug Administration (FDA) approval in 1998 and European Medicines Agency (EMA) approval in 2000 for use in the treatment of metastatic HER2-positive (HER2+) breast cancer. Subsequently, the FDA and EMA approved trastuzumab as an adjuvant treatment for HER2 + breast cancer and HER2+ metastatic gastric or gastroesophageal junction adenocarcinoma [1,2].

Trastuzumab was recently included in the World Health Organization (WHO)'s list of essential cancer drugs [3, 4]; co-administration with other drugs has become the standard of care in HER2-overexpressing breast cancers in the (neo)adjuvant and first-line palliative settings. Its use varies according to the indication: alone or in combination with chemotherapy, hormone therapy, small-molecule tyrosine kinase inhibitors, and other antibodies, such as pertuzumab [5-9].

Despite being considered a breakthrough in HER2+ breast cancer treatment, the high cost of trastuzumab makes access to this drug a challenge, mainly in undeveloped countries, resulting in a worse prognosis for breast cancer patients [10, 11]. Since 2017, after patent expiration, some trastuzumab biosimilars have been approved in several countries [12-17] (Table 1), and their use has been strongly supported by the European Society of Medical Oncology [18]. 
Table 1 List of trastuzumab biosimilars of Herceptin ${ }^{\circledR}$ (Roche) approved in the USA, Brazil, and Europe [12-17]

\begin{tabular}{llll}
\hline Biosimilar & Company & Approved by & Date \\
\hline Ogivri $^{\circledR a}$ & Mylan/Biocon & FDA & 1 December 2017 \\
Zedora $^{\circledR a}$ & $\begin{array}{l}\text { Mylan/Biocon/ } \\
\text { Libbs }\end{array}$ & ANVISA & 18 December 2017 \\
Ontruzant $^{\circledR}$ & Samsung Bioepis & EMA & 15 November 2017 \\
Herzuma $^{\circledR}$ & Celltrion Healthcare & EMA & 9 February 2018 \\
Kanjinti $^{\circledR}$ & Amgen & EMA & 16 May 2018 \\
Trazimera $^{\circledR}$ & Pfizer & EMA & 26 July 2018 \\
\hline
\end{tabular}

ANVISA Agência Nacional de Vigilância Sanitária, EMA European Medicines Agency, FDA US Food and Drug Administration

${ }^{\text {aZedora }}{ }^{\circledR}$ (trastuzumab), the brand name marketed in Brazil by Libbs Farmacêutica, and Ogivri ${ }^{\circledR}$ (trastuzumab-dkst) are the same product

According to the label recommendation, the intravenous (IV) formulation of trastuzumab can be administered in weekly infusions (initial dose of $4 \mathrm{mg} / \mathrm{kg}$ followed by subsequent doses of $2 \mathrm{mg} / \mathrm{kg}$ ) or every 3 weeks (initial dose of $8 \mathrm{mg} / \mathrm{kg}$ followed by subsequent doses of $6 \mathrm{mg} / \mathrm{kg}$ ), depending on the indication and regimen chosen. The first dose might be infused in $90 \mathrm{~min}$, with all additional doses administered within 30-90 min if the patient has no infusion reactions [1].

The subcutaneous (SC) administration of drugs initially approved to be given intravenously is a developing strategy that aims for an overall pharmacoeconomic benefit and/or the patient's comfort [19-21]. In certain cases, such as in $\mathrm{SC}$ bortezomib to treat multiple myeloma, it may even result in improved safety, as the rate of adverse effects might be reduced [22].

For drug manufacturers, the reformulation of existing drugs is also a valuable strategy to remain competitive as the expiration of patents approaches as these new formulations can guarantee extended patent protection [23]. In the case of monoclonal antibodies, newer versions could be protected against competing biosimilars, such as the SC formulation of trastuzumab [24].

\section{Trastuzumab Reformulation}

The SC trastuzumab formulation contains the same monoclonal antibody found in the IV formulation in a dose of $600 \mathrm{mg} / 5 \mathrm{~mL}$ per vial plus a recombinant human hyaluronidase (rHuPH20, 10,000 $\mathrm{U}$ ) to be used in a fixed dose of $600 \mathrm{mg}$ every 3 weeks, independent of the patient's weight. The combination with a hyaluronidase was necessary to increase the permeability of the extracellular matrix, which allows the administration of higher volumes and enhances drug absorption into the circulation [25]; to this purpose, $\mathrm{HuPH} 20$ has been considered an attractive
Table 2 Timeline approval of trastuzumab in different formulations and indications by FDA and EMA $(1,2)$

\begin{tabular}{lll}
\hline Formulation & Date of approval \\
\cline { 2 - 3 } & FDA & EMA \\
\hline IV TZB mBC & September 1998 & August 2000 \\
IV TZB eBC & November 2006 & May 2006 \\
IV TZB mGEJaC & October 2010 & December 2009 \\
SC TZB mBC & NA & June 2013 \\
SC TZB eBC & NA & June 2013 \\
SC TZB mGEJaC & NA & NA \\
\hline
\end{tabular}

$e B C$ early breast cancer, EMA European Medicines Agency, FDA US Food and Drug Administration, $I V$ intravenous, $m B C$ metastatic breast cancer, $m G E J a C$ metastatic gastric or gastroesophageal junction adenocarcinoma, $N A$ non-approved, $S C$ subcutaneous, $T Z B$ trastuzumab

option for delivering large molecules (i.e., monoclonal antibodies, immunoglobulins, or insulin) and fluid volumes via the SC route as an alternative to IV administration given its modest immunogenicity and lack of adverse events and deleterious effects on efficacy [26].

In the HannaH study, a phase III, multicenter, international, randomized, open-label non-inferiority trial, SC and IV formulations of trastuzumab were compared in the neoadjuvant setting [27]. The study, which included 596 patients, succeeded in proving the noninferiority of the SC formulation in terms of efficacy [measured as complete pathological response (pCR) rate and pharmacokinetics (co-primary endpoints)]. The pCR rate was 40.7\% [95\% confidence interval (CI) 34.7-46.9] for the IV formulation and $45.4 \%$ (95\% CI 39.2-51.7) for the SC formulation, and the pCR difference was $4.7 \%$ (95\% CI -4.0 to 13.4), which fits within the pre-established non-inferiority margin of $-12.5 \%$. The co-primary pharmacokinetic endpoint [geometric mean ratio of serum trough concentrations $\left(C_{\text {trough }} \mathrm{SC} / C_{\text {trough }} \mathrm{IV}\right)$ at cycle 7 (before surgery)] was 1.33 (90\% CI 1.24-1.44), which is non-inferior according to the prespecified non-inferiority margin (ratio should be $\geq 0.8$ ) [28].

The safety profile was considered similar, but serious adverse events were more common with the SC formulation ( $21.0 \%$ vs. $12.0 \%$; $p$ value not reported), mainly attributable to infections and infestations [27]. The results of the SC trastuzumab trials were considered relevant and motivated its approval by the EMA and Agência Nacional de Vigilância Sanitária (ANVISA) to treat early HER2+ breast cancer, and through extrapolation of efficacy and safety data it was also approved to treat metastatic HER2+ breast cancer. However, to date, SC trastuzumab is not a biologic approved by the FDA (a Biologics License Application was accepted on 11 July 2018) and is not approved for metastatic gastric cancer treatment in Europe or Brazil (Table 2). 


\section{Immunogenicity}

One of the main concerns regarding the use of biologicals is their immunogenicity potential. Immunogenicity is the capacity of a therapeutic protein, such as a monoclonal antibody, to be recognized by the immune system as a foreign protein and to elicit the production of anti-drug antibodies (ADAs). There is a wide spectrum of potential clinical manifestations related to the immunogenic response against the drug: loss of efficacy, neutralization of the natural counterpart, and worsening of the safety profile (especially in the immune-related adverse events, such as allergy, anaphylaxis, or serum sickness) [20, 29-31]. Considering the importance of this issue, immunogenicity assessment and comparison are required in the guidelines of biosimilar development [32-34] and, to be approved, biosimilars have to prove equivalent immunogenicity [35].

There are many potential factors that may influence the immunogenicity of therapeutic proteins: structural features (sequence variation and glycosylation), storage conditions (denaturation, or aggregation caused by oxidation), contaminants or impurities in the preparation, length of treatment, and route of administration; all of these factors play a role in the complex interactions between the patient's body and the biological drug [20, 30, 36].

For some drugs, the $\mathrm{SC}$ route of administration was associated with a higher risk of immunogenicity than the IV route, but the identification of definitive causal factors is a difficult task, as several potential factors are often present, such as differences in IV and SC formulation composition and product attributes, and dose or dose frequency differences between the IV and SC routes [20,36].

Antibodies produced secondary to an immunogenic response from the patient's immune system against the biological can be classified into three groups according to their action: neutralizing; non-neutralizing, but with elimination-modifying activity; and non-neutralizing with no effect on the pharmacokinetic profile. Neutralizing antibodies prevent the therapeutic proteins from acting effectively by preventing them from binding to their pharmacological targets. On the other hand, the non-neutralizing antibodies have no effect on the ability of the protein to interact with its target, but they may lessen the therapeutic effectivity of the drug by interfering with the pharmacokinetic profile due to enhanced elimination secondary to the formation of immune complexes [37].

The final immunogenicity analysis of the HannaH study published by Jackisch et al. [28] showed that the ADA rates were $7.1 \%(21 / 296)$ with IV trastuzumab and $14.6 \%$ (43/295) with SC trastuzumab. The rates of neutralizing ADAs (nADAs) were also evaluated, and were detected in only one patient in the IV group and two patients in the SC group. No formal hypothesis test was reported for these analyses, but the Fisher's exact test suggests a two-fold significant association between developing overall trastuzumab ADAs and receiving the SC formulation $(p=0.003)$; meanwhile, there was no association when nADAs were analyzed $(p=0.62)$ [28].

An important aspect that must be mentioned is that efficacy parameters, such as $\mathrm{pCR}$ and the serum concentration of trastuzumab, were evaluated and the presence of ADA did not interfere with the $\mathrm{pCR}$ rate or with the pharmacokinetic profile; additionally, no association was found between ADAs and infusion reactions. Based on these findings, the elicited anti-trastuzumab antibodies were deemed to have no clinical relevance, as they were considered non-neutralizing and had no influence on the pharmacokinetic profile [28].

Another issue that should be considered in the clinical development of biologicals such as trastuzumab is that immunogenicity elicited against a non-autologous protein may produce antibody responses that are more intense and long lasting due to $\mathrm{T}$ cell-dependent activation of $\mathrm{B}$ cells, with potential for the development of memory B cells [38-40]. Approximately $47 \%$ of all patients who tested positive for ADAs in the HannaH study had ADAs detected in the treatment-free follow-up period [41, 42].

\section{Patients' Preference}

The greatest benefit of SC trastuzumab over the IV formulation is related to its route of administration. The PrefHer study evaluated 467 patients, of whom 235 received four cycles of SC trastuzumab (2-5 min administration) followed by four cycles of IV trastuzumab ( 90 min for the first loading dose infusion, $30 \mathrm{~min}$ for subsequent infusions) and 232 received treatment in a reverse sequence. This study was conducted to determine which administration route women preferred best, and showed that the majority of patients preferred the SC route (88.9\%; 95\% CI 85.7-91.6; $p<0.0001$ ) [21]. Women chose the $\mathrm{SC}$ administration as their preferred option because it was associated with less pain or discomfort and considered "time saving", as one patient stated: "with this [SC formulation] it was 'Hello' and 'Bye' without having to spend hours with patients" [21]. However, despite the lack of a specific recommendation for the observation period post-injection in the pivotal trial [43], according to the IV and SC trastuzumab labels the recommended observation period for signs or symptoms of administration-related reactions is similar: $6 \mathrm{~h}$ after the start of the first infusion (IV) or after the first injection (SC), and $2 \mathrm{~h}$ after the start of the subsequent infusions (IV) or after the subsequent injections (SC) [2]. To date, regulatory constraints may prevent patients from taking advantage of the fastest administration of SC trastuzumab, which is one of its most important 
benefits. This recommendation also prevents another possible benefit: home administration or the self-administration of the SC variant, one of the rationales for the pivotal study, which could increase convenience and patients' compliance over the treatment period [43].

The safety profiles of SC and IV trastuzumab were considered comparable, as the PrefHer study identified that adverse events of any grade based on the National Cancer Institute Common Terminology Criteria for Adverse Events (NCI-CTCAE) occurred in $61.0 \%$ of patients treated with the SC formulation and in $51.3 \%$ of those treated with the IV formulation. Most of this difference was due to grade 1 or 2 reactions at the site of injection, mainly pain or erythema [21].

\section{Trastuzumab-Pertuzumab Interactions}

One of the main issues regarding trastuzumab biological activity is the interaction with pertuzumab. The combination of these two monoclonal antibodies has been widely tested and is approved to treat HER2+ breast cancer in the metastatic [9] and (neo)adjuvant [44-46] settings.

In silico simulations suggested that pertuzumab and trastuzumab clinical synergism arises "partly from an enhanced affinity that originates from the cooperative interactions

(A)

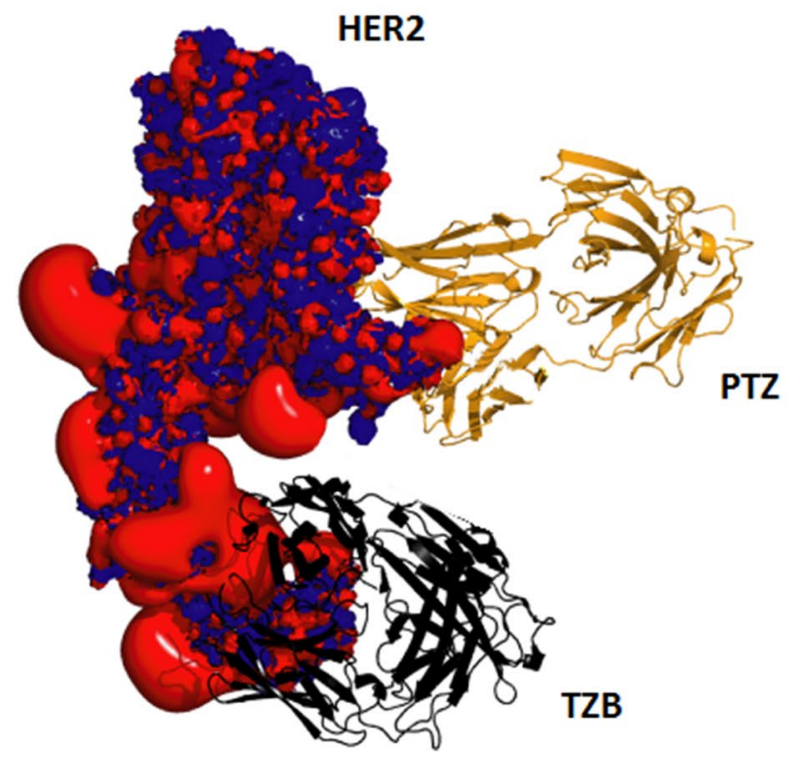

Fig. 1 Representation of the in silico pertuzumab (PTZ; orange)induced trastuzumab (TZB; black) epitope that emerges during the course of the molecular dynamics (MD) simulations of the HER2 ectodomain (HER2; red-blue electrostatic surface where red represents regions of acidity and blue represents regions of basicity). a between the two antibodies when they are co-localized on HER2 and "clamp it"" [47] (Fig. 1a, b).

In the HannaH study, approximately $15 \%$ of patients in the SC trastuzumab group had detectable ADAs [28], which were classified as non-neutralizing antibodies and showed no impact on the pharmacokinetic profile. The expected interaction of the trastuzumab-ADA complex at the HER2 receptor level in the absence of pertuzumab resulted in no clinical impact on the efficacy or safety profile.

However, interactions among HER2 receptor, pertuzumab, and trastuzumab-ADA complexes have not been evaluated; accordingly, the presence of these complexes should not be ignored, as the expected interaction must happen in a coordinated manner and in very close sites. It is still unknown how the trastuzumab-ADA complex would work in the presence of pertuzumab at the HER2 level and how it would affect the efficacy or safety profile.

The SAPPHIRE study is a multicenter, open-label, phase IIIb study that intended to evaluate the safety, tolerability, and efficacy of IV pertuzumab plus SC trastuzumab and a taxane selected by the investigator in 50 patients treated for HER $2+$ metastatic breast cancer. The safety profile was consistent with the results of previous studies, and the combination was considered safe and tolerable. However, the different taxanes used and the small population enrolled made it difficult to draw definitive conclusions regarding safety and efficacy [48].

\section{(B)}

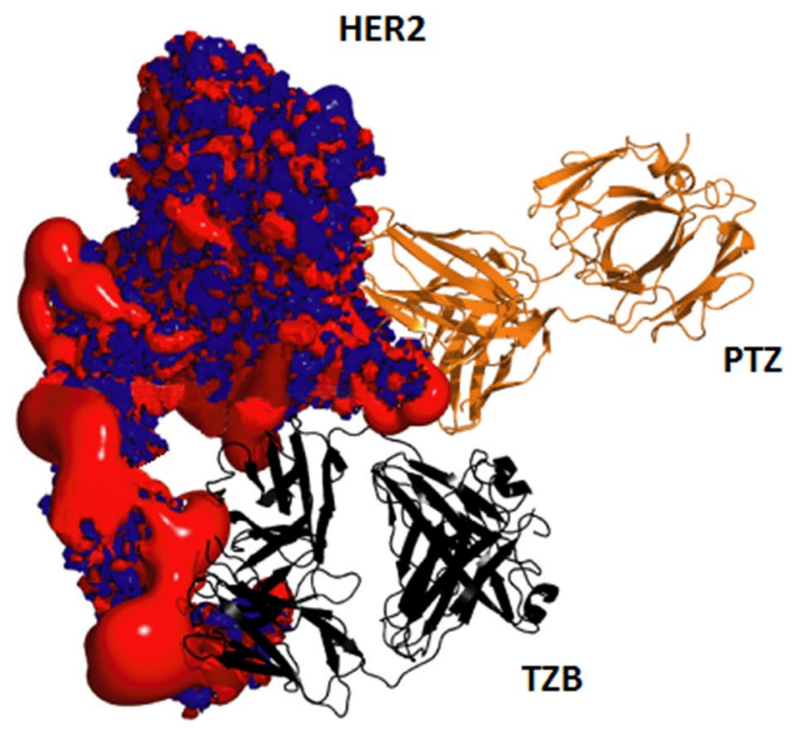

HER2-trastuzumab complex structure at the beginning of the simulation showing no contact between trastuzumab and the new epitope and $\mathbf{b}$ snapshot taken during the MD simulation showing interactions between trastuzumab and the new epitope. Adapted from images published by Fuentes et al. [47] 
The MetaPHER study is an ongoing phase IIIb multicenter, open-label, single-arm study that intends to evaluate the safety and efficacy of using SC trastuzumab in combination with IV pertuzumab and docetaxel in the first-line treatment of patients with HER2 + advanced breast cancer. With an estimated sample size of 418 patients, the first reports are expected by March 2019 (NCT02402712) [49]. The results of this trial are expected to allow for a better understanding of the potential risks due to the increased immunogenicity elicited by SC trastuzumab in the synergistic effect of the trastuzumab and pertuzumab combination.

\section{Discussion}

SC trastuzumab stands out as an option to treat early and advanced HER2+ breast cancer with more convenient administration and time and cost savings [50]. Clinical trials have proven its non-inferiority to the IV formulation in terms of efficacy and safety; higher immunogenicity was identified but considered to be of no clinical significance. Based on these findings, the European and Brazilian regulatory agencies (EMA and ANVISA, respectively) have already approved SC trastuzumab and its use in clinical practice is a reality $[2,51]$.

In this scenario, some potential risks must be noted so that medical oncologists and regulatory agencies remain vigilant in order to guarantee patient safety. The first aspect to note is that the use of the SC trastuzumab was associated with a higher development of ADAs when used as sole monoclonal antibodies in the adjuvant or neoadjuvant settings but without clinical relevance [28]. Although these ADAs are deemed not to interfere with drug function or pharmacokinetics when SC trastuzumab is administered without any other monoclonal antibody, their impact on the molecular synergistic interaction of trastuzumab and pertuzumab at the HER2 level when they are given concomitantly has not yet been assessed. The MetaPHER study is expected to shed light on this question, but the comparative efficacy will not be assessed as it is a one-arm trial [49].

It also remains unclear if, in the unfortunate case of a tumor recurrence, patients from the SC group would have higher immune system long-lasting memory ADAs and how this would impact the safety and efficacy of a subsequent treatment line using IV trastuzumab and IV pertuzumab (as currently approved).

The SC formulation of trastuzumab has been associated with time and cost savings [50, 52]. However, considering costs, updated pharmacoeconomic studies investigating the current scenario of biosimilar arrival would be of great value once the average price of IV trastuzumab formulations has been reduced [11].

\section{Conclusion}

SC trastuzumab is a treatment option for patients with HER 2+ breast cancer, especially in those who do not require any other IV medication, and for those who wish to use a more convenient treatment option, and is of benefit to drug manufacturers for patent protection against competing biosimilars. As research evolves in this specific field, new insights regarding its immunogenicity and its clinical implications will be achieved. Today's perspective is that it is safe for use as a monotherapy, but oncologists and regulatory agencies must be alerted to identify subtle harms that might pass unnoticed in pivotal trials for approving the drug.

Author Contributions All authors contributed to the writing of this manuscript and have read and approved the final version of the manuscript.

\section{Compliance with Ethical Standards}

Funding No external funding was used in the preparation of this manuscript. Open access was funded by Libbs Farmacêutica.

Conflict of interest Franklin Fernandes Pimentel has participated in a consulting or advisory role for Libbs Farmacêutica and has received speaker honorarium from AstraZeneca and Libbs Farmacêutica. Gilberto Morgan, Daniel Guimarães Tiezzi, and Jurandyr Moreira de Andrade declare that they have no conflicts of interest that might to be relevant to the contents of this manuscript.

Open Access This article is distributed under the terms of the Creative Commons Attribution-NonCommercial 4.0 International License (http://creativecommons.org/licenses/by-nc/4.0/), which permits any noncommercial use, distribution, and reproduction in any medium, provided you give appropriate credit to the original author(s) and the source, provide a link to the Creative Commons license, and indicate if changes were made.

\section{References}

1. Biologic License Application (BLA): 103792. Company: Genentech. Herceptin-trastuzumab. Drugs@ FDA: FDA approved drug products. 2017. https://www.accessdata.fda.gov/scripts/cder/daf/ index.cfm?event $=$ overview.process $\& A p p l N o=103792$. Accessed 22 Aug 2018.

2. Herceptin (trastuzumab). European Medicines Agency-Science Medicines Health. 2000. http://www.ema.europa.eu/docs/en_GB/ document library/EPAR _ Product Information/human/000278/ WC500074922. Accessed 22 Aug 2018.

3. Shulman LN, Torode J, Wagner C, Lopes GL Jr, Barr R, Magrini N. WHO expands cancer essential medicines list. ASCO Daily News. 2016. http://am.asco.org/daily-news/who-expands-cance r-essential-medicines-list. Accessed 22 Aug 2018.

4. Shulman LN, Wagner CM, Barr R, Lopes G, Longo G, Robertson $\mathrm{J}$, et al. Proposing essential medicines to treat cancer: methodologies, processes, and outcomes. J Clin Oncol. 2016;34(1):69-75.

5. Vogel CL, Cobleigh MA, Tripathy D, Gutheil JC, Harris LN, Fehrenbacher L, et al. Efficacy and safety of trastuzumab as a 
single agent in first-line treatment of HER2-overexpressing metastatic breast cancer. J Clin Oncol. 2002;20(3):719-26.

6. Slamon DJ, Leyland-Jones B, Shak S, Fuchs H, Paton V, Bajamonde A, et al. Use of chemotherapy plus a monoclonal antibody against HER 2 for metastatic breast cancer that overexpresses HER2. N Engl J Med. 2001;344(11):783-92.

7. Piccart-Gebhart MJ, Procter M, Leyland-Jones B, Goldhirsch A, Untch M, Smith I, et al. Trastuzumab after adjuvant chemotherapy in HER2-positive breast cancer. N Eng1 J Med. 2005;353(16):1659-72.

8. Kaufman B, Mackey JR, Clemens MR, Bapsy PP, Vaid A, Wardley A, et al. Trastuzumab plus anastrozole versus anastrozole alone for the treatment of postmenopausal women with human epidermal growth factor receptor 2-positive, hormone receptorpositive metastatic breast cancer: results from the randomized phase III TAnDEM study. J Clin Oncol. 2009;27(33):5529-37.

9. Baselga J, Cortés J, Kim SB, Im SA, Hegg R, Im YH, et al. Pertuzumab plus trastuzumab plus docetaxel for metastatic breast cancer. N Engl J Med. 2012;366(2):109-19.

10. Debiasi M, Reinert T, Kaliks R, Amorim G, Caleffi M, Sampaio $\mathrm{C}$, et al. Estimation of premature deaths from lack of access to anti-HER2 therapy for advanced breast cancer in the Brazilian public health system. J Glob Oncol. 2017;3(3):201-7.

11. Debiasi M, Pimentel FF, Pereira PJS, Barrios CH. Biosimilars in Brazil: the beginning of an era of broader access. J Cancer Ther. 2017;8:814-26.

12. FDA approves first biosimilar for the treatment of certain breast and stomach cancers. U.S. Food and Drug Administration. 2017. https://www.fda.gov/Drugs/InformationOnDrugs/ApprovedDr ugs/ucm587404.htm. Accessed 22 Aug 2018.

13. Zedora (trastuzumabe). Bulário Eletrônico ANVISA-Agência Nacional de Vigilância Sanitária. 2017. http://www.anvisa.gov.br/ datavisa/fila_bula/frmVisualizarBula.asp?pNuTransacao $=58508$ 62018\&pIdAnexo=10634297. Accessed 22 Aug 2018.

14. Ontruzant (trastuzumab). European Medicines Agency (EMA). 2017. http://www.ema.europa.eu/ema/index.jsp?curl=pages /medicines/human/medicines/004323/human_med_00218 8.jsp\&mid=WC0b01ac058001d124. Accessed 22 Aug 2018.

15. Herzuma (trastuzumab). European Medicines Agency (EMA). 2018. http://www.ema.europa.eu/ema/index.jsp?curl=pages /medicines/human/medicines/002575/human_med_00223 0.jsp\&mid=WC0b01ac058001d124. Accessed 22 Aug 2018.

16. Kanjinti (trastuzumab). European Medicines Agency (EMA). 2018. http://www.ema.europa.eu/ema/index.jsp?curl=pages /medicines/human/medicines/004361/human_med_00225 5.jsp\&mid=WC0b01ac058001d124. Accessed 22 Aug 2018.

17. Trazimera (trastuzumab). European Medicines Agency (EMA). 2018. http://www.ema.europa.eu/ema/index.jsp?curl=pages /medicines/human/medicines/004463/human med_00228 2.jsp\&mid=WC0b01ac058001d124. Accessed 22 Aug 2018.

18. Cardoso F, Senkus E, Costa A, Papadopoulos E, Aapro M, André $\mathrm{F}$, et al. 4th ESO-ESMO International Consensus Guidelines for Advanced Breast Cancer (ABC 4). Ann Oncol. 2018;29(8):1634-57.

19. Papadmitriou K, Trinh XB, Altintas S, Van Dam PA, Huizing MT, Tjalma WA. The socio-economical impact of intravenous (IV) versus subcutaneous (SC) administration of trastuzumab: future prospectives. Facts Views Vis Obgyn. 2015;7(3):176-80.

20. Hamuro L, Kijanka G, Kinderman F, Kropshofer H, Bu DX, Zepeda M, et al. Perspectives on subcutaneous route of administration as an immunogenicity risk factor for therapeutic proteins. J Pharm Sci. 2017;106(10):2946-54

21. Pivot X, Gligorov J, Müller V, Curigliano G, Knoop A, Verma S, et al. PrefHer Study Group. Patients' preferences for subcutaneous trastuzumab versus conventional intravenous infusion for the adjuvant treatment of HER2-positive early breast cancer: final analysis of 488 patients in the international, randomized, twocohort PrefHer study. Ann Oncol. 2014;25(10):1979-87.

22. Moreau P, Pylypenko H, Grosicki S, Karamanesht I, Leleu X, Grishunina M, et al. Subcutaneous versus intravenous administration of bortezomib in patients with relapsed multiple myeloma: a randomised, phase 3, non-inferiority study. Lancet Oncol. 2011;12(5):431-40.

23. Steffe EK, Nannenga-Combs B, Longsworth GL. The impact of reformulation strategies on pharmaceuticals, biologics. Biosimilar Development. 2016. https://www.biosimilardevelopment.com/ doc/the-impact-of-reformulation-strategies-on-pharmaceuticals -biologics-0001. Accessed 22 Aug 2018.

24. Stanton D. Roche getting under the skin of biosimilar competition. In-Pharma Technologist. 2016. https://www.in-pharmatechnolog ist.com/Article/2016/07/25/Roche-getting-under-the-skin-of-biosi milar-competition. Accessed 22 Aug 2018.

25. Hamizi S, Freyer G, Bakrin N, Henin E, Mohtaram A, Le Saux O, et al. Subcutaneous trastuzumab: development of a new formulation for treatment of HER2-positive early breast cancer. Onco Targets Ther. 2013;6:89-94.

26. Rosengren S, Dychter SS, Printz MA, Huang L, Schiff RI, Schwarz HP, et al. Clinical immunogenicity of rHuPH20, a hyaluronidase enabling subcutaneous drug administration. AAPS J. 2015;17(5):1144-56.

27. Ismael G, Hegg R, Muehlbauer S, Heinzmann D, Lum B, Kim $\mathrm{SB}$, et al. Subcutaneous versus intravenous administration of (neo) adjuvant trastuzumab in patients with HER2-positive, clinical stage I-III breast cancer (HannaH study): a phase 3, open-label, multicentre, randomised trial. Lancet Oncol. 2012;13(9):869-78.

28. Jackisch C, Kim SB, Semiglazov V, Melichar B, Pivot X, Hillenbach C, et al. Subcutaneous versus intravenous formulation of trastuzumab for HER2-positive early breast cancer: updated results from the phase III HannaH study. Ann Oncol. 2015;26(2):320-5.

29. Schellekens H. Immunogenicity of therapeutic proteins: clinical implications and future prospects. Clin Ther. 2002;24(11):1720 40 (discussion 19).

30. Schellekens H. Factors influencing the immunogenicity of therapeutic proteins. Nephrol Dial Transpl. 2005;20(Suppl 6):vi3-9.

31. Schellekens H. Bioequivalence and the immunogenicity of biopharmaceuticals. Nat Rev Drug Discov. 2002;1(6):457-62.

32. Scientific considerations in demonstrating biosimilarity to a reference product: guidance for industry. U.S. Department of Health and Human Services, Food and Drug Administration, Center for Drug Evaluation and Research (CDER), Center for Biologics Evaluation and Research (CBER). 2015. https://www.fda.gov/ downloads/drugs/guidances/ucm291128.pdf. Accessed 22 Aug 2018.

33. Guideline on similar biological medicinal products containing biotechnology-derived proteins as active substance: non-clinical and clinical issues. European Medicines Agency (EMA). 2014. http://www.ema.europa.eu/docs/en_GB/document_library/Scien tific_guideline/2015/01/WC500180219.pdf. Accessed 22 Aug 2018.

34. Resolução-RDC No. 55, de 16 de dezembro de 2010. Ministério da Saúde, Agência Nacional de Vigilância Sanitária (ANVISA). 2010. http://bvsms.saude.gov.br/bvs/saudelegis/anvisa/2010/anexo /anexo_res0055_16_12_2010.pdf. Accessed 22 Aug 2018.

35. Rugo HS, Barve A, Waller CF, Hernandez-Bronchud M, Herson $\mathrm{J}$, Yuan J, et al. Effect of a proposed trastuzumab biosimilar compared with trastuzumab on overall response rate in patients with ERBB2 (HER2)-positive metastatic breast cancer: a randomized clinical trial. JAMA. 2017;317(1):37-47.

36. Schellekens H. The immunogenicity of therapeutic proteins. Discov Med. 2010;9(49):560-4. 
37. Chirmule N, Jawa V, Meibohm B. Immunogenicity to therapeutic proteins: impact on PK/PD and efficacy. AAPS J. 2012;14(2):296-302.

38. De Groot AS, Moise L. Prediction of immunogenicity for therapeutic proteins: state of the art. Curr Opin Drug Discov Dev. 2007;10(3):332-40.

39. Jawa V, Cousens LP, Awwad M, Wakshull E, Kropshofer H, De Groot AS. T-cell dependent immunogenicity of protein therapeutics: preclinical assessment and mitigation. Clin Immunol. 2013;149(3):534-55.

40. Krishna M, Nadler SG. Immunogenicity to biotherapeutics-the role of anti-drug immune complexes. Front Immunol. 2016;7:21.

41. Hegg R, Pienkowski T, Chen S, Staroslawska E, Falcon S, Kovalenko $\mathrm{N}$, et al. Immunogenicity of trastuzumab intravenous and subcutaneous formulations in the phase III HannaH study [poster no. 273P]. Vienna: ESMO; 2012 (28 Sep-2 Oct 2012).

42. Jackisch C, Scappaticci FA, Heinzmann D, Bisordi F, Schreitmüller T, Minckwitz G, et al. Neoadjuvant breast cancer treatment as a sensitive setting for trastuzumab biosimilar development and extrapolation. Future Oncol. 2015;11(1):61-71.

43. Jackisch C, Hegg R, Stroyakovskiy D, Ahn JS, Melichar B, Chen $\mathrm{SC}$, HannaH phase III randomised study, et al. Association of total pathological complete response with event-free survival in HER2-positive early breast cancer treated with neoadjuvantadjuvant trastuzumab after 2 years of treatment-free follow-up. Eur J Cancer. 2016. https://ars.els-cdn.com/content/image/1-s2.0S0959804916320494-mmc2.pdf. Accessed 22 Aug 2018 [Appendix A. Supplementary data. Roche Protocol BO22227 C (Ro 45-2317). ed2016. p. 1-103].

44. Gianni L, Pienkowski T, Im YH, Roman L, Tseng LM, Liu MC, et al. Efficacy and safety of neoadjuvant pertuzumab and trastuzumab in women with locally advanced, inflammatory, or early HER2-positive breast cancer (NeoSphere): a randomised multicentre, open-label, phase 2 trial. Lancet Oncol. 2012;13(1):25-32.

45. Schneeweiss A, Chia S, Hickish T, Harvey V, Eniu A, Hegg R, et al. Pertuzumab plus trastuzumab in combination with standard neoadjuvant anthracycline-containing and anthracycline-free chemotherapy regimens in patients with HER2-positive early breast cancer: a randomized phase II cardiac safety study (TRYPHAENA). Ann Oncol. 2013;24(9):2278-84.
46. von Minckwitz G, Procter M, de Azambuja E, Zardavas D, Benyunes M, Viale G, et al. Adjuvant pertuzumab and trastuzumab in early HER2-positive breast cancer. N Engl J Med. 2017;377(2):122-31.

47. Fuentes G, Scaltriti M, Baselga J, Verma CS. Synergy between trastuzumab and pertuzumab for human epidermal growth factor 2 (Her2) from colocalization: an in silico based mechanism. Breast Cancer Res. 2011;13(3):R54.

48. Woodward N, De Boer RH, Redfern A, White M, Roberts W, Truman $\mathrm{M}$ et al. Updated safety results from the first multicenter, open-label, phase IIIb study investigating the combination of pertuzumab with subcutaneous trastuzumab and a taxane in patients with HER2-positive metastatic breast cancer (SAPPHIRE) [abstract]. In: Proceedings of the 2016 San Antonio Breast Cancer Symposium; 2016 Dec 6-10; San Antonio, TX. Philadelphia (PA): AACR; Cancer Res 2017;77(4 Suppl):Abstract nr P4-21-31.

49. Kümmel S, Abraham J, Martin M, Crepelle-Fléchais A, Swat A, Nüesch E, et al. MetaPHER phase IIIb multicenter, open-label, single-arm safety study of subcutaneous trastuzumab in combination with pertuzumab and docetaxel in patients with HER2-positive advanced breast cancer: first results [abstract no. P4-21-42]. In: Proceedings of the 2016 San Antonio Breast Cancer Symposium, vol. 77, no. 4 Suppl. San Antonio, Philadelphia: AACR. Cancer Res; 2017. pp. P4-21-42 (6-10 Dec 2016).

50. Samanta K, Moore L, Jones G, Evason J, Owen G. Potential time and costs savings with Herceptin (trastuzumab) subcutaneous (SC) injection versus Herceptin intravenous (IV) infusion: results from three different English patients settings [abstract no. PCN39]. Value Health. 2012;15(7):A415.

51. Herceptin ${ }^{\circledR}$ SC (trastuzumabe). Bulário Eletrônico ANVISAAgência Nacional de Vigilância Sanitária. 2018. http://www.anvis a.gov.br/datavisa/fila_bula/frmVisualizarBula.asp?pNuTransac ao=113342018\&pIdAnexo=10415252. Accessed 22 Aug 2018.

52. Tjalma WAA, Van den Mooter T, Mertens T, Bastiaens V, Huizing MT, Papadimitriou K. Subcutaneous trastuzumab (Herceptin) versus intravenous trastuzumab for the treatment of patients with HER2-positive breast cancer: a time, motion and cost assessment study in a lean operating day care oncology unit. Eur J Obstet Gynecol Reprod Biol. 2018;221:46-51. 